\title{
Reclamation Tax Calculation at Revenue Service, Regional Financial and Asset Management (Dppkad) Pariaman City (Perhitungan Pajak Reklamepada Dinas Pendapatan, Pengelola Keuangan Dan Aset Daerah (Dppkad) Kota Pariaman)
}

\author{
Zefriyenni $^{1}$, Firna Yenila ${ }^{2}$, Yogi Wiyandra ${ }^{3}$ \\ ${ }^{1}$ Fakultas Ekonomi dan Bisnis, Univesitas Putra Indonesia "YPTK" Padang \\ ${ }^{2}$ Fakultas Ilmu Komputer, Univesitas Putra Indonesia "YPTK" Padang \\ ${ }^{3}$ Fakultas Ilmu Komputer, Univesitas Putra Indonesia "YPTK" Padang \\ E-mail: zefriyenni@upiyptk.ac.id, firnayenila@upiyptk.ac.id, yogiwiyandra@upiyptk.ac.id
}

\begin{abstract}
Abstrak
Perhitungan pajak reklame yang dilakukan oleh Dinas Pendapatan, Pengelolaan Keuangan dan Aset (DPPKA) Kab. Dharmasraya masih menggunakan sistem manual sehingga kinerja menjadi tidak optimal. Penelitian yang dilakukan bertujuan untuk mengoptimalkan perhitungan pajak reklame dan memberikan waktu pelayanan secara cepat kepada pengguna iklan dan pembayar pajak. Dengan penelitian ini diharapkan dapat membantu pihak DPPKA dalam melakukan perhitungan pajak reklame secara efektif dan efesien. Metode penelitian yang digunakan adalah penelitian lapangan,penelitian perpustakaan dan laboratorium. Sehingga dihasilkan sebuah analisa sistem baru dengan menggunakan alat bantu seperti Use Case Diagram, Sequence Diagram, Class Diagram, Activity Diagram dan Deployment Diagram.
\end{abstract}

Kata kunci:Pajak, reklame, sistem informasi

\section{Abstract}

Billboard tax calculations conducted by the Revenue, Financial and Asset Management Agency (DPPKA) Kab. Dharmasraya still uses a manual system so that performance is not optimal. The research conducted aims to optimize the calculation of advertisement tax and provide fast service time for ad users and taxpayers. With this research, it is expected to be able to assist the DPPKA in calculating the advertisement tax effectively and efficiently. The research methods used are field research, library research and laboratories. So that a new system analysis is produced by using tools such as Use Case Diagrams, Sequence Diagrams, Class Diagrams, Activity Diagrams and Deployment Diagrams.

Keywords: tax, billboards, information systems

\section{Pendahuluan}

Dinas Pendapatan, Pengelola keuangan dan Aset (DPPKAD) Kota Pariaman merupakan dinas yang mengelola keuangan dan aset daerah di Kota Pariaman, dimana keuangan tersebut berasal dari pajak daerah, retribusi daerah, hasil kekayaan daerah yang dipisahkan dan pendapatan asli daerah lainnya yang disahkan.

Perpajakan merupakan salah satu sarana pemerataan pendapatan warga negara dan sumber dana pembangunan negara bagi pemerintah[2]. Menurut UU KUP NOMOR 28 TAHUN 2007, pasal 1, ayat 1, pengertian Pajak adalah kontribusi wajib kepada negara yang terutang oleh orang pribadi atau badan yang bersifat memaksa berdasarkan undang-undang, dengan tidak mendapatkan imbalan secara langsung dan digunakan untuk keperluan negara bagi sebesar-besarnya kemakmuran rakyat[1].

Iklan menjadi salah satu strategi pemasaran utama di kalangan pebisnis maupun oleh perusahaan untuk menggaet banyak konsumen. Dengan kegiatan promosi di berbagai media, masyarakat akan kenal dengan produk atau jasa kita, mencoba, dan akhirnya menjadi pelanggan yang loyal. Meski beriklan 
harus merogoh duit banyak, termasuk untuk membayar kewajiban pajak ini itu, namun sebanding dengan keuntungan yang akan kita dapatkan[5]

Di samping itu, kebutuhan perusahaan atau pebisnis untuk terus beriklan, menjadi peluang usaha menjanjikan untuk merintis bisnis di bidang periklanan. Jika kesulitan mencari modal usaha, sekarang banyak pilihan, seperti Kredit Tanpa Agunan (KTA), Kredit Multiguna (KMG), maupun pinjaman online resmi dan terpercaya.

Dalam menjalankan kegiatannya padaproses perhitungan pajak reklame pada Dinas Pendapatan, Pengelola keuangan dan Aset (DPPKAD) Kota Pariamansudah menggunakan komputer secara global namun belum secara mutlak sistem kerjanya dilakukan dengan keseluruhan, data diolah menggunakan Microsoft Office secara keseluruhan. Hal tersebutmasih dinyatakan kurang efisien untuk ibu kota sebesar Pariaman, dimana proses pengolahan pajak reklame memakan waktu yang lama dan dapat membuka ruang untuk terjadinya kesalahan dalam perhitungan pajak reklame serta menimbulkan kesan seakan-akan tidak adanya transparansi biaya pada pengurusannya, selain itu memungkinkan terjadinya kecurangan dalam perhitungan biaya.

Umumnya perhitungan pajak reklamesecara online dengan menggunakan bahasa pemrograman PHP, dimana dengan adanya aplikasi ini dapat lebih memudahkan pihak Dinas Pendapatan, Pengelola keuangan dan Aset DAERAH (DPPKAD) Kota Pariaman dalam melakukan pengolahan perhitungan pajak reklame serta data yang dihasilkan nantinya akan lebih tepat, cepat dan akurat.

\section{Tinjauan Literatur}

\subsection{Pajak}

Pajak merupakan pungutan wajib yang dibayar rakyat untuk negara dan akan digunakan untuk kepentingan pemerintah dan masyarakat umum. Rakyat yang membayar pajak tidak akan merasakan manfaat dari pajak secara langsung, karena pajak digunakan untuk kepentingan umum, bukan untuk kepentingan pribadi [4].

Besaran pajak reklame untuk kalkulasinya sudah ada ketentuan yang berlaku yaitu sebesar $25 \%$ dari NSR (Nilai Sewa Reklame). Mengenai besaran atau jumlah pajak reklame itu sangat tergantung pada faktor yang mempengaruhi tentang besaran nilai sewa reklame (NSR) tersebut[6]

Faktor-faktor yang mempengaruhi besaran NSR sangat ditentukan oleh siapa penyelenggara reklame, jenis reklame (produk atau non-produk), dan juga faktor lainnya.. Untuk reklame yang diselenggarakan sendiri, besaran NSR ditentukan oleh beberapa faktor berikut ini:[7]

1. Jenis reklame

2. Lokasi

3. Kategori kelas jalan

4. Jumlah Reklame

5. Bahan yang digunakan

6. Ukuran

7. Jangka waktu pemasangan

8. Waktu pemasangan

NSR atau Nilai Sewa Reklame merupakan dasar pengenaan pajak dan menjadi salah satu faktor dalam perhitungan pajak reklame terutang. Sedangkan jika kita sudah mengetahui nilai sewa reklame kita bisa menghitung pajak reklame yang merupakan pajak atas penyelenggaraan reklame.[8]

\subsection{Sistem Informasi}


Sistem informasi terdiri dari komponen-kompponen yang disebut dengan istilah blok bangunan (Building Block), dimana masing-masing blok ini saling berintegrasi satu sama lainnya untuk membentuk satu kesatuan dalam mencapai tujuan sesuai dengan yang dikonsepkan/dibuat[3].

\section{Metodologi}

Dalam melakukan penelitian agar mendapat hasil seperti yang diharapkan, maka diperlukan kerangka kerja penelitian, dimana kerangka penelitian yang dilakukan digambarkan seperti Gambar 3.1

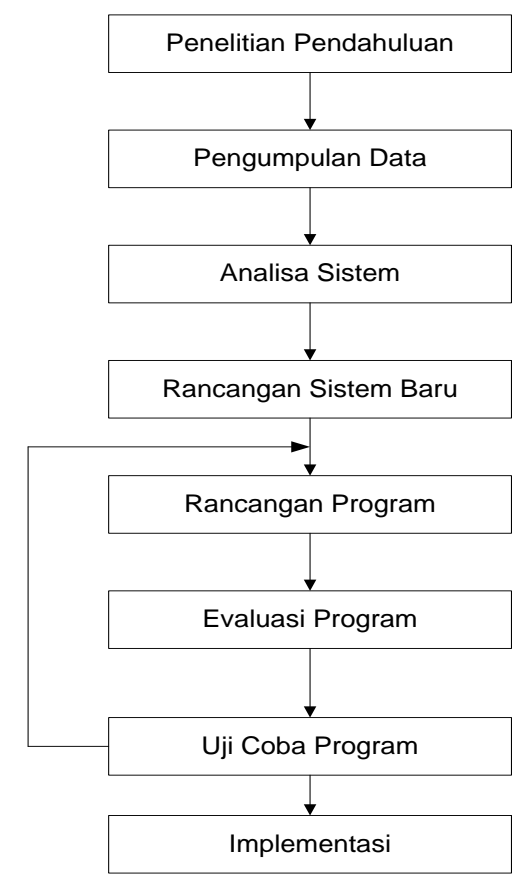

Gambar 3.1 Metodologi Penelitian

\section{Analisa dan hasil}

Sistem informasi perpajakan reklame biasanya masih dilakukan secara manual, kalaupun sudah menggunakan komputer pemakaiannya masih belum optimal semisal microsoft office atau bakan hanya melibatkan microsoft word dan microsoft excel.

Perancangan sistem informasi perpajakan reklame ini membutuhkan beberapa aktor yang terhubung dalam sistem diantaranya 




Gambar 4.1 Use case Diagram

Aktifitas pemrograman ditampilkan dalam bentuk dibawah ini:

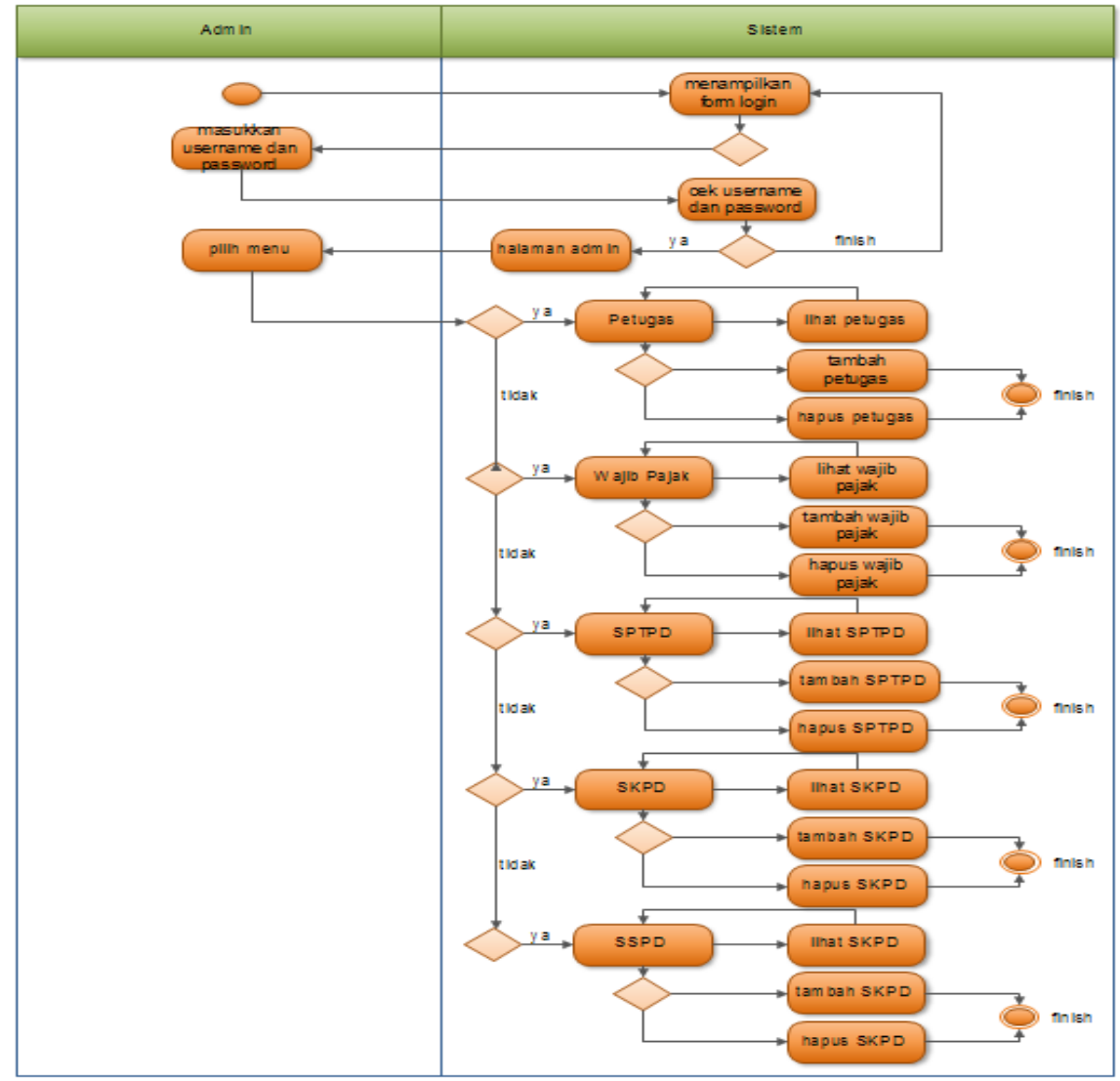

Gambar 4.2 Use case Diagram

\section{Implementasi Sistem}

Tahap implementasi sistem merupakan salah satu tahap dalam daur hidup pengembangan sistem, dimana tahap ini merupakan tahap agar sistem informasi siap untuk dipakai. Dalam tahap ini berlangsung beberapa aktifitas secara berurutan yakni mulai darimenerapkan rencana implementasi, melakukan kegiatan implementasi, dan tindak lanjut implementasi. 
Layout awal yang dimunculkan dalam penelitian ini adalah sebagai berikut:

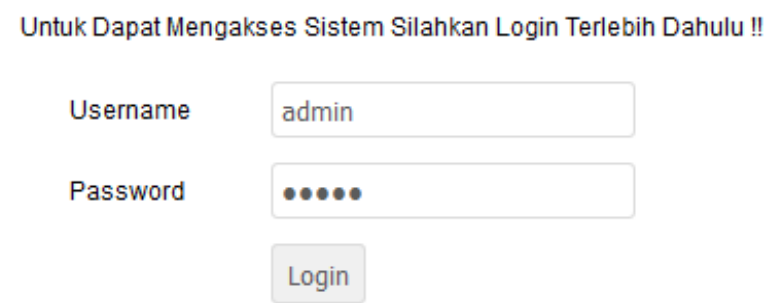

Gambar 5.1 Log In

Tampilan berikutnya adalah menciptakan salah satu report yang dibutuhkan dalam pengolahan data pajak atau perhitungan pajak.

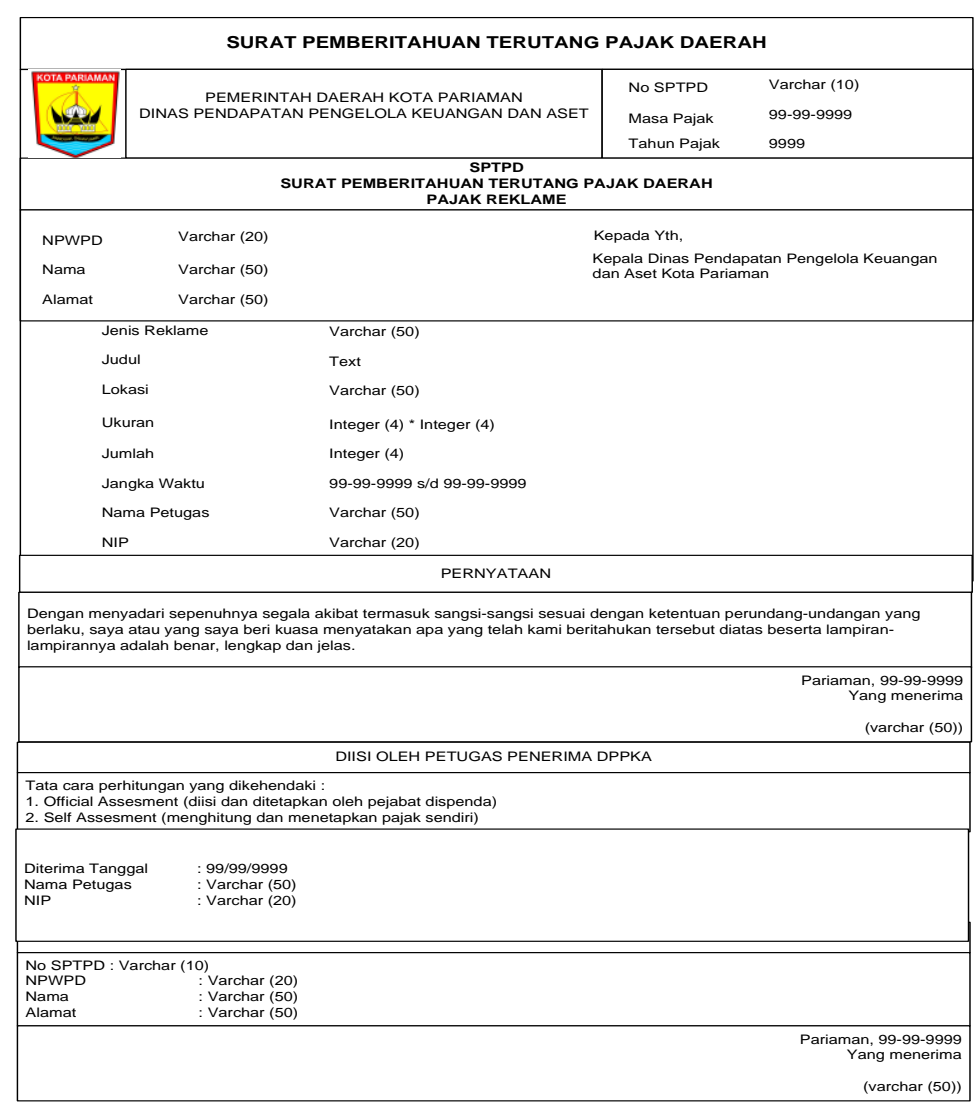

Gambar 5.2 Entri SPTPD 


\section{Kesimpulan} berikut :

Berdasarkan analisa dan pembahasan yang telah dilakukan, maka dapat diambil kesimpulan sebagai

a. Dengan adanya aplikasi Sistem informasiperhitungan pajak reklame ini, pegawai DPPKADKota Pariaman dapat dengan mudah mengelola data pajak reklame dan proses pengolahan data akan lebih cepat dan akurat.

b. Dengan pengoptimalan pemakaian komputerisasi dalam pengolahan data akan meningkatkan efektifitas dan efesiensi kerja sehingga mempercepat laju kegiatan perhitungan pajak reklame di Kantor DPPKADKota Pariaman

c. Sistem yang baru ini mampu melakukan perhitungan terhadap biaya pajak reklame yang harus dikeluarkan oleh pemohon.

\section{Referensi}

[1]Authors/Task Force Members:, Perk, J., De Backer, G., Gohlke, H., Graham, I., Reiner, Ž., ... \& Cifkova, R. (2012). European Guidelines on cardiovascular disease prevention in clinical practice (version 2012) The Fifth Joint Task Force of the European Society of Cardiology and Other Societies on Cardiovascular Disease Prevention in Clinical Practice (constituted by representatives of nine societies and by invited experts) Developed with the special contribution of the European Association for Cardiovascular Prevention \& Rehabilitation (EACPR). European heart journal, 33(13), 1635-1701.

[2] Forastiere, A. A., Goepfert, H., Maor, M., Pajak, T. F., Weber, R., Morrison, W., ... \& Peters, G. (2003). Concurrent chemotherapy and radiotherapy for organ preservation in advanced laryngeal cancer. New England Journal of Medicine, 349(22), 2091-2098.

[3] Sutabri, T. (2012). Analisis sistem informasi. Penerbit Andi.

[4] Chomsatu, Y., \& Asih, S. (2016, October). Pengaruh Prinsip Keadilan Dan Struktur Tarif Pajak Terhadap Keikutsertaan Program Amnesti Pajak. In Seminar Nasional Fakultas Ekonomi UNIBA Surakarta (Vol. 2, No. 1, pp. 338-347).

[5] Azizah, D. A. (2017). Strategi Komunikasi Kantor Wilayah Direktorat Jenderal Pajak (Kanwil Djp) Yogyakarta Dalam Mengajak Wajib Pajak Untuk Membayar Pajak Tahun 2015-2016.

[6] Lucvany, S. (2015). Analisis Perbedaan Pajak Penghasilan Terutang Berdasarkan Norma Penghitungan Dengan Pph Final Wajib Pajak Orang Pribadi Usahawan Di Bidang Usaha Jasa Pada Kpp Pratama PurworejoProgram Studi Akuntansi. Fakultas Ekonomi, Universitas Atma Jaya Yogyakarta.

[7] Ananda, P. R. D. (2015). Pengaruh Sosialisasi Perpajakan, Tarif Pajak, dan Pemahaman Perpajakan terhadap Kepatuhan Wajib Pajak (Studi pada UMKM yang Terdaftar sebagai Wajib Pajak di Kantor Pelayanan Pajak Pratama Batu). Jurnal Mahasiswa Perpajakan, 6(2).

[8] Putra, R. R. R. (2014). Pengaruh Sanksi Administrasi Sosialisasi Perpajakan dan Kesadaran Wajib Pajak terhadap Kepatuhan Penyampaian Spt Tahunan Wajib Pajak Orang Pribadi (Studi di Kantor Pelayanan Pajak Pratama Singosari, Kabupaten Malang). Jurnal Mahasiswa Perpajakan, 1(1). 